http://jmscr.igmpublication.org/home/

ISSN (e)-2347-176x ISSN (p) 2455-0450

crossref DOI: https://dx.doi.org/10.18535/jmscr/v9i6.15

Journal Of Medical Science And Clinical Research

IGM Publication

An Official Publication of IGM Publication

\title{
Help-seeking behaviour of patients attending outpatient of state mental health hospital
}

\author{
Authors \\ Abhilaksh Kango ${ }^{1}$, Anukriti Singh ${ }^{2}$ \\ ${ }^{1}$ Psychiatrist, Himachal Hospital of Mental Health and Rehabilitation, Shimla (HP) \\ ${ }^{2}$ Medical officer, IGMC, Shimla (HP) \\ Corresponding Author \\ Dr Abhilaksh Kango
}

Psychiatrist, Himachal Hospital of Mental Health and Rehabilitation, Shimla (HP), 171005, India

\begin{abstract}
Aim: To study the help-seeking behaviour of patients attending outpatient of $H H M H \& R$, Shimla.

Material and Methods: A cross-sectional observation was done on patients attending outpatient in our hospital to analyse the help seeking patterns of care used by them. Information related to sociodemographic features, clinical characteristics was collected and subjected to a semi-structured interview schedule after informed consent.

Results: Traditional faith healers were first choice in 23 (32.4\%) followed by physician, alternative medicine. Only few patients (1.4\%) opted to visit psychiatrist as first choice. Main reasons to visit various facilities first were due to easy accessibility (26.8\%) and main reason to visit us was lack of response $(43.7 \%)$.

Conclusion: Mentally ill Patients look for help due to multiple reasons from psychiatrists, general physicians, faith healers and alternative medicine. It is cardinal to educate various general physicians which will help in early detection and proper treatment of mental health issues.

Keywords: Himachal Hospital of Mental Health and Rehabilitation (HHMH\&R).
\end{abstract}

\section{Introduction}

Knowledge of the various help seeking pattern for psychiatric illness is important to plan for various trainings, mental health reforms and improving mental health services. ${ }^{1}$ Various reasons to opt for a specific service aid in gaining knowledge that how people recognizes mental illnesses and retort to them. This information can be used in making various awareness plans and to address various misunderstandings and inform the population with the accessibility of several facilities available for aid. In previous studies it is seen that, in our country $2-5 \%$ of the people are affecting from severe psychiatric illness, whereas other $10 \%$ of the people are affected with minor psychiatric disorders. ${ }^{2}$ It is seen that most of patients with psychiatric illness never look for any qualified help and resort to general physicians or traditional faith healers. Various reasons for this is sparsity of qualified professionals, stigma or beliefs associated along with negative attitudes of caregivers toward patient. ${ }^{3}$ The vastly dominant superstitious beliefs linked to psychiatric illness and lower education mainly in backward regions, 
pose substantial social hindrances in looking for suitable facility for mentally ill persons.

Our study also focus on exploring and analysing different health care options used by participants with psychiatric illness and also what explanation they give for same.

\section{Materials and Methods}

The study was done at HHMH \& R Shimla in February and March 2021 in cross-sectional pattern. Patients attending the outpatient who were accompanied by family members were included in study after they were explained properly about the study and informed consent. A semi-structured interview was done to collect the information. ${ }^{4}$ Data collected comprised of details about demographics, illness duration, ICD -10 diagnosis, several categories of facilities accessed before coming to the our facility, explanation for visiting our facility.

\section{Statistical Analysis}

Analysis of Data was done using SPSS software. Descriptive statistics (i.e. mean, standard deviation was used for continuous variables and frequencies were used for categorical variables).

\section{Results}

The sample consisted of 71 participants out of which Table 1: - Sample characteristics 44 were males and 27 were females. Mean age of sample was $42.75 \pm 10.61$ years. Around $64 \%$ patients were married. Around $58 \%$ of participants were employed. Majority of patients had psychotic disorders $(52.1 \%)$ followed by mood disorders (33.8\%). Mean duration of illness was 70.52 years.

\section{[Table 1]}

\begin{tabular}{|c|c|}
\hline Variables & $\begin{array}{c}\text { Patients } \\
\text { N=71 } \\
\text { Mean (SD)/ Frequency }(\%)\end{array}$ \\
\hline Age in years & $42.75(10.61)$ \\
\hline $\begin{array}{l}\text { Gender } \\
\text { Male } \\
\text { Female }\end{array}$ & $\begin{array}{l}44(62 \%) \\
27(38 \%)\end{array}$ \\
\hline $\begin{array}{l}\text { Marital status } \\
\text { Single } \\
\text { Married }\end{array}$ & $\begin{array}{l}25(36.2 \%) \\
46(64.8 \%)\end{array}$ \\
\hline $\begin{array}{l}\text { Occupation } \\
\text { Unemployed } \\
\text { Employed }\end{array}$ & $\begin{array}{l}30(42.3 \%) \\
41(58.4 \%)\end{array}$ \\
\hline Duration of illness & $70.52(121.4)$ \\
\hline $\begin{array}{l}\text { Diagnosis } \\
\text { Psychotic } \\
\text { Mood disorders } \\
\text { Others }\end{array}$ & $\begin{array}{l}37(52.1 \%) \\
24(33.8 \%) \\
10(14.1 \%)\end{array}$ \\
\hline
\end{tabular}

\section{Services used by patients}

The most common service used was Physicians as first choice $(40.8 \%)$ followed by traditional faith healers $(32.4 \%)$ and alternative medicine $(25.4 \%)$. However around $25 \%$ participants opted to visit psychiatrist as second choice but $40 \%$ of patients still opted for physician as second choice.[Table 2]

In reasons to choose various facilities most common reason reported was easy accessibility
(26.8\%) followed by belief in various systems of medicine $(25.4 \%)$, supernatural causation $(21 \%)$ and recommendation by family/friends $(22.5 \%)$. [Table 3]

In reasons to visit our facility most common reason was lack of response $(43.7 \%)$ followed by low cost of treatment (25.4\%), someone recommendation and for second opinion. [Table 4]

Table 2: Various services used by patients previously 


\begin{tabular}{|l|c|c|c|}
\hline Contact healer & First choice of visit & Second choice of visit & Third choice of visit \\
\hline Traditional faith healer & $23(32.4 \%)$ & $06(8.5 \%)$ & $01(1.4 \%)$ \\
\hline Alternative medicine & $18(25.4 \%)$ & $12(16.9 \%)$ & $01(1.4 \%)$ \\
\hline Physician & $29(40.8 \%)$ & $29(40.8 \%)$ & $01(1.4 \%)$ \\
\hline Psychiatrist & $01(1.4 \%)$ & $18(25.4 \%)$ & $09(12.7 \%)$ \\
\hline
\end{tabular}

Table 3: Reasons for opting several treatment facilities

\begin{tabular}{|l|c|}
\hline Reasons to choose & Frequency (\%) \\
\hline Easily accessible & $19(26.8 \%)$ \\
\hline Belief in system & $18(25.4 \%)$ \\
\hline Supernatural causation of illness & $15(21.1 \%)$ \\
\hline Less expenditure & $02(2.8 \%)$ \\
\hline Recommendation by family/friends & $16(22.5 \%)$ \\
\hline
\end{tabular}

Table 4: Explanations provided by patients for visiting us

\begin{tabular}{|l|c|}
\hline Reasons to visit us & Frequency (\%) \\
\hline Someone recommendation & $10(14.1 \%)$ \\
\hline Lack of response & $31(43.7 \%)$ \\
\hline Prior contact with us & $02(2.8 \%)$ \\
\hline Lower cost of treatment & $18(25.4 \%)$ \\
\hline Just for second opinion & $10(14.1 \%)$ \\
\hline
\end{tabular}

\section{Discussion}

The main finding from the study was physicians followed by traditional faith healers were the most common opted service by participants with psychiatric illness. In past studies done in North India, psychiatrist was reported as first choice by $58 \%$ of the participants, whereas psychiatric hospital was only visited by one third participants. ${ }^{4}$ Alike findings were seen in study done in psychiatric hospital in South India. ${ }^{5}$ However In a recent study in Madhya Pradesh done in psychiatric hospital ${ }^{6}$ it was observed that first choice of service providers was faith healers in $68 \%$ of participants. In this study most common diagnosis was psychotic disorders. The first two studies, were conducted in metropolitan cities due to which most of participants were from urban background whereas the third study majority of participants were from rural area. As number of qualified mental health professionals is much lower in Madhya Pradesh which can be a major reason for people to visit faith healers. Which is also the case in our state.

In our observation easy accessibility of services, belief in various system, and someone recommendation were common reasons provided by participants. Due to stigma associated with psychiatric illness people tend to visit faith healers. $^{7}$

It is apparent that the satisfaction with the treatment from psychiatrist was reasonable and treatment was often continued. It was perhaps as the psychiatrist was opted as last option by the participants and they continued the treatment for long.

It's been recommended for amalgamation of mental health with primary care is more apt strategy and will succeed. ${ }^{8}$ Which also comprises educating programs in mental health for various professionals dealing with patients suffering from mental illness. ${ }^{9}$ As mentally ill patients often opt to consult general physicians which also include primary care doctors so it is necessary to train them to identify early and manage properly various psychiatricissues. ${ }^{10}$ However, it is tough to generalize the observations as it included participants who were seeking treatment from hospital. As it is seen that majority of mentally ill patients even in the developed nations never look for treatment ${ }^{11,12}$, so the findings are prejudiced for patients that has a decent health-seeking attitude.

In conclusion, it is apparent that in our nation mentally ill people seek help from various 
facilities like general physicians, faith healers, alternative medicine and psychiatrists. Recently, people who have common mental disorders also seek help. It is necessary to educate physicians to identify the mental health issues early and manage them properly and refer for professional help if needed. Likewise, to reduce the delays in help seeking there should be proper awareness programs should be in place.

\section{References}

1. Gater R, de Almeida e Sousa B, Barrientos G, Caraveo J, Chandrashekar CR, Dhadphale $\mathrm{M}$, et al. The pathways to psychiatric care: A cross-cultural study. Psychol Med. 1991;21:761-74.

2. National Institute of Health and Family Welfare. National Mental Health Program. New Delhi: NIHFW; 2005.

3. Rogler LH, Cortes DE. Help-seeking pathways: A unifying concept in mental health care. Am J Psychiatr. 1993;150:554-61.

4. Chadda RK, Agarwal V, Singh MC, Raheja D. Help seeking behaviour of psychiatric patients before seeking care at a mental hospital. Int J Soc Psychiatry. 2001;47:71-8.

5. Janakiramaiah $\mathrm{N}$, Badrinath $\mathrm{B}$, Channabasavanna SM, Kaliaperumal VG.Dealing with deviant behaviour. Indian J Psychiatry. 1979;21:206-10.

6. Lahariya C, Singhal S, Gupta S, Mishra A. Pathway of care among psychiatric patients attending a mental health institution in central India. Indian $\mathbf{J}$ Psychiatry. 2010;52:333-8.

7. Loganathan S, Murthy RS. Experiences of stigma and discrimination endured by people suffering from schizophrenia. Indian J Psychiatry. 2008;50:39-46.

8. Weiss M, Sharma SD, Gaur RK, Sharma JS, Desai A, Doongaji DR. Traditional concepts of mental disorder among Indian psychiatric patients: Preliminary report of work in progress. Soc Sci Med. 1986;2: 379-86.

9. Government of India. National Mental Health Programme for India. Government of India, New Delhi: Ministry of Health and Family Welfare; 1982.

10. Chadda RK, Sood M, Kumar N. Experiences of a sensitization program on common mental disorders for primary care physicians using problem basedlearning approach. Indian J Psychiatry. 2009; 51:289-91.

11. Kessler RC, McGonagle KA, Zhao S, Nelson CB, Hughes M, Eshleman S, et al. Lifetime and 12-month prevalence of DSM-III-R psychiatric disorders in the United States. Results from the National Comorbidity Survey. Arch Gen Psychiatry. 1994;51:8-19.

12. Regier DA, Farmer ME, Rae DS, Myers JK, Kramer M, Robins LN, et al. Onemonth prevalence of mental disorders in the United States and sociodemographic characteristics: The Epidemiologic Catchment Area study. Acta Psychiatr Scand. 1993;88:35-47. 